\title{
Speed-Dependent Contribution of Callosal Pathways to Ipsilateral Movements
}

\author{
Toshiki Tazoe ${ }^{1,2}$ and Monica A. Perez ${ }^{1}$ \\ ${ }^{1}$ Department of Physical Medicine and Rehabilitation, Center for the Neural Basis of Cognition, Systems Neuroscience Institute, University of Pittsburgh, \\ Pittsburgh, Pennsylvania 15261 and ${ }^{2} J a p a n$ Society for the Promotion of Science, Tokyo, 102-0083, Japan
}

\begin{abstract}
Transcallosal inhibitory interactions between primary motor cortices are important to suppress unintended movements in a resting limb during voluntary activation of the contralateral limb. The functional contribution of transcallosal inhibition targeting the voluntary active limb remains unknown. Using transcranial magnetic stimulation, we examined transcallosal inhibition [by measuring interhemispheric inhibition (IHI) and the ipsilateral silent period (iSP)] in the preparatory and execution phases of isotonic slower self-paced and ballistic movements performed by the ipsilateral index finger into abduction and the elbow into flexion in intact humans. We demonstrate decreased IHI in the preparatory phase of self-paced and ballistic index finger and elbow movements compared to rest; the decrease in IHI was larger during ballistic than self-paced movements. In contrast, in the execution phase, IHI and the iSP increased during ballistic compared to self-paced movements. Transcallosal inhibition was negatively correlated with reaction times in the preparatory phase and positively correlated with movement amplitude in the execution phase. Together, our results demonstrate a widespread contribution of transcallosal inhibition to ipsilateral movements of different speeds with a functional role during rapid movements; at faster speeds, decreased transcallosal inhibition in the preparatory phase may contribute to start movements rapidly, while the increase in the execution phase may contribute to stop the movement. We argue that transcallosal pathways enable signaling of the time of discrete behavioral events during ipsilateral movements, which is amplified by the speed of a movement.
\end{abstract}

\section{Introduction}

Transcallosal interactions between primary motor cortices (M1s) are thought to contribute to control unilateral movements (Chen et al., 1997; Hübers et al., 2008; Perez and Cohen, 2008; Beaulé et al., 2012). For example, transcallosal inhibition targeting a resting hand is important to suppress unintended movements during activation of the contralateral hand (Cincotta and Ziemann, 2008; Giovannelli et al., 2009). In the active limb, studies have reported that transcallosal inhibition is present during voluntary activity (Ferbert et al., 1992) and decreases compared to rest (Gerloff et al., 1998; Ridding et al., 2000; Chen et al., 2003). The functional contribution of transcallosal inhibition to ipsilateral movements, however, remains unknown (Perez, 2012).

Animal studies have proposed that neural activity in callosal neurons enable signaling the time of behavioral events (Soteropoulos and Baker, 2007). In awake primates, callosal neurons respond largely during ballistic compared to other components of an arm motor task (Soteropoulos and Baker, 2007). Studies in humans have hypothesized that transcallosal inhibition targeting

\footnotetext{
Received June 21, 2013; revised Aug. 8, 2013; accepted Sept. 4, 2013.

Author contributions: T.T. and M.A.P. designed research; T.T. and M.A.P. performed research; T.T. and M.A.P. contributed unpublished reagents/analytic tools; T.T. and M.A.P. analyzed data; T.T. and M.A.P. wrote the paper.

This work was supported by The National Institute of Neurological Disorders and Stroke, NIH (R01 NS076589 to M.A.P.), and Japan Society for the Promotion of Science (JSPS Fellows \#23-10759 to T.T.).

Correspondence should be addressed to Dr. Monica A. Perez, Department of Physical Medicine and Rehabilitation, Center for the Neural Basis of Cognition, University of Pittsburgh, 3501 Fifth Avenue, Pittsburgh, PA 15261. E-mail: perezmo@pitt.edu.

DOI:10.1523/JNEUROSCI.2638-13.2013

Copyright $\odot 2013$ the authors $\quad 0270-6474 / 13 / 3316178-11 \$ 15.00 / 0$
}

an active limb contributes to control the timing of muscle activation (Meyer and Voss, 2000; Davare et al., 2007) and motor learning processes, resulting in changes in the speed of motor responses (Kobayashi, 2010; Zimerman et al., 2012). Furthermore, transcallosal inhibition decreases in individuals with faster compared to slower reaction times (RTs) in the ipsilateral hand after a motor learning task (Perez et al., 2007). Thus, if transcallosal pathways are responsive to changes in the speed of a movement, it is important to understand how interhemispheric inhibition is modulated during ipsilateral movements of different speeds.

The activity in the M1 shows different activation patterns in the preparatory phase of upcoming slow and fast movements in animals (Churchland et al., 2006) and humans (Chen et al., 1998; Leocani et al., 2000); then, it is possible that transcallosal pathways also showed different patterns of activity. Indeed, transcallosal inhibition progressively decreases during the preparatory phase of fast movements compared to rest (Murase et al., 2004; Duque et al., 2005; Liuzzi et al., 2010). The increases in movement speed also results in increments in electromyographic (EMG) activity during movement execution. Electrophysiological studies showed that activity in the ipsilateral motor cortex increases during increments in EMG activity (Stedman et al., 1998; Muellbacher et al., 2000; Hortobágyi et al., 2003; Perez and Cohen, 2008), and increased corticospinal excitability results in larger interhemispheric inhibition in the ipsilateral limb (Lee et al., 2007). Therefore, we hypothesized that transcallosal inhibition targeting an active limb will decrease in the preparatory and increase in the execution phase of ipsilateral movements of in- 
A FINGER TASK
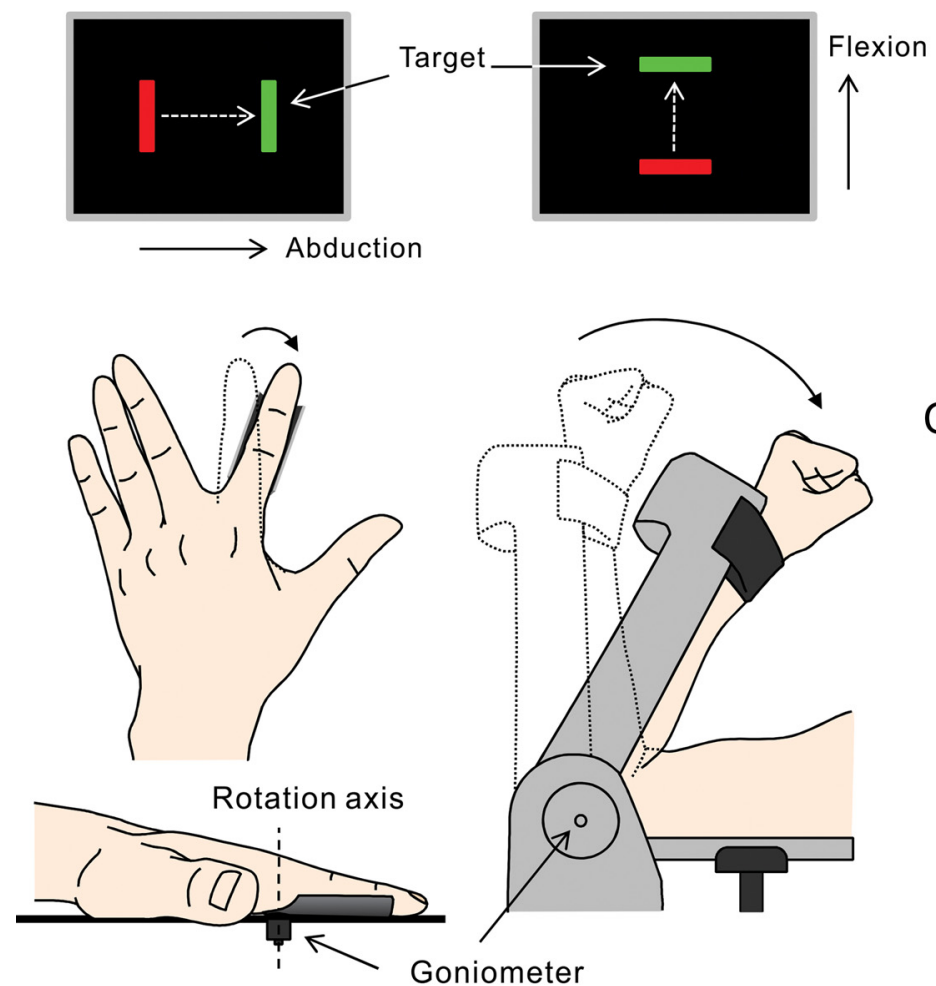

$\mathrm{B}$

Self-paced
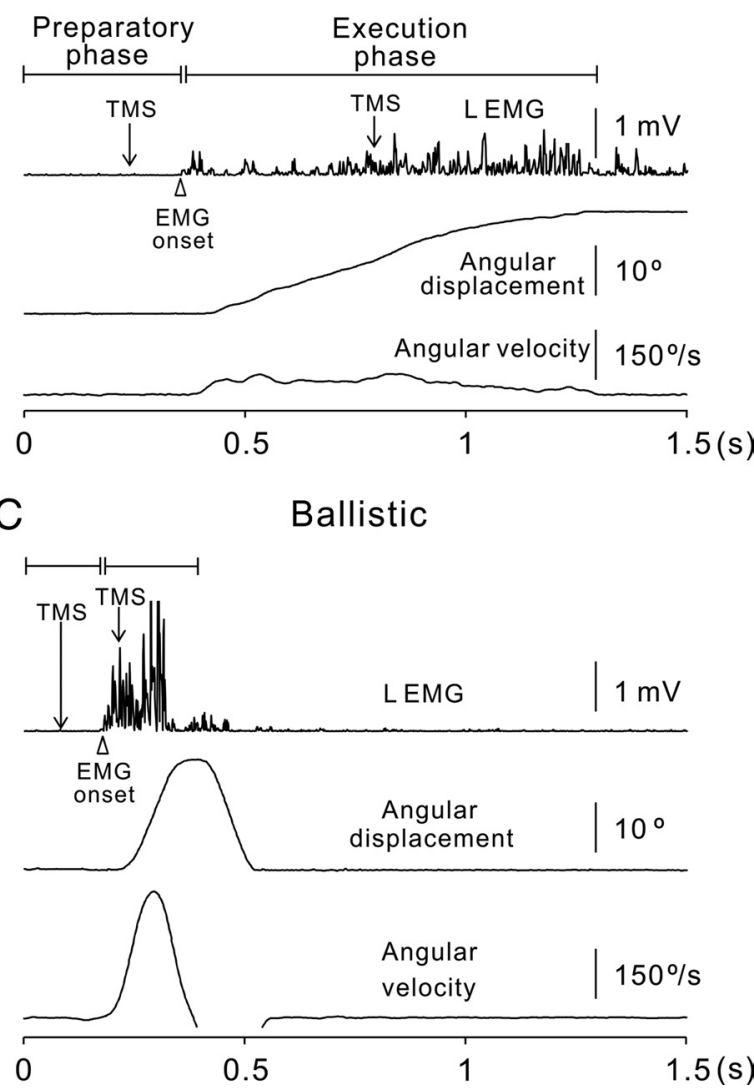

$1.5(\mathrm{~s}$

Figure 1. Experimental setup. A, Diagram showing the visual display presented to subjects during testing. Subjects were instructed to perform self-paced and ballistic index finger abduction and elbow flexion movements. Schematic of the experimental setup showing the posture of the hand and elbow used during testing (bottom illustration). Raw traces show EMG activity of the left FDI muscle, angular displacement of the metacarpophalangeal joint of the index finger, and angular velocity of the same joint during self-paced $(\boldsymbol{B})$ and ballistic $(\boldsymbol{C})$ index finger movements. Arrows indicate the time at which TMS given in the preparatory and execution phases of self-paced and ballistic movements.

creasing speeds. We also predicted that movement speed will affect similarly distal and proximal arm muscles due to shared control mechanisms between these cortical representations (Soteropoulos and Perez, 2011; Perez et al., 2012).

To test our hypothesis, we used transcranial magnetic stimulation (TMS) over the ipsilateral motor cortex to measure interhemispheric inhibition (IHI) and the ipsilateral silent period (iSP; Ferbert et al., 1992), indirect measures of transcallosal activity, in the preparatory and execution phases of slower selfpaced and ballistic index finger and elbow movements. We demonstrate a speed-dependent functional contribution of transcallosal inhibition to ipsilateral movements of rapid speed.

\section{Materials and Methods}

Subjects

Twenty four right-handed healthy volunteers $(32.8 \pm 13.4$ years old, 15 females) participated in the study. All subjects gave informed consent to the experimental procedures, which were approved by the local ethics committee at the University of Pittsburgh and were in accordance with the guidelines established in the Declaration of Helsinki.

\section{EMG recordings}

EMG activity was recorded bilaterally from the first dorsal interosseous (FDI) and biceps brachii (BB) muscles through surface electrodes (Ag$\mathrm{AgCl} ; 10 \mathrm{~mm}$ diameter) secured to the skin over the belly of each muscle. EMG signals were amplified and filtered (bandwidth, 30-1000 Hz) with a bioamplifier (NeuroLog System; Digitimer). The angular displacement of index finger abduction and elbow flexion were recorded by potentiometers (SP30S-10; ETI Systems). All signals were stored on a computer with sampling rate of $2 \mathrm{kHz}$ using a CED $1401 \mathrm{~A} / \mathrm{D}$ converter (Cambridge Electronic Design) for later off-line analysis.

\section{Experimental paradigm}

Subjects participated in a finger and an elbow task. During the finger task, subjects were seated in a chair with the left and right arms flexed at the elbow at $90^{\circ}$, forearm pronated, and the wrist restrained by straps. The tested left index finger was positioned in a half-cylindrical object that was connected to a rotating axis with a potentiometer around the metacarpophalangeal joint (Fig. 1A, left). During the elbow task, the right arm was maintained in the same position as described above while the left shoulder was flexed at $90^{\circ}$ and the elbow flexed at $90^{\circ}$ with the forearm supinated and the wrist restrained by straps (Fig. 1A, right). A custombuilt arm device was used to maintain the position of the left arm with a potentiometer attached to measure elbow flexion. At the start of each experiment, subjects performed three brief maximal voluntary contractions (MVCs) for 3-5 s into index finger abduction and elbow flexion, separated by $30 \mathrm{~s}$. In addition, maximal angular displacement into index finger abduction and elbow flexion were acquired by a custom-built program (LabVIEW). Maximal angular displacement was used to set targets for subsequent submaximal movements. At the beginning of each trial, an auditory go signal and a visual target were presented indicating the amplitude of the movement. To examine physiological measurements at the same level of EMG activity in the FDI and the BB, the visual target was located at a distance corresponding to $20^{\circ}$ of index finger abduction in the finger task and $30^{\circ}$ of elbow flexion in the elbow task. During each task, subjects were instructed to complete the movement at two different speeds after a go signal: as fast as possible (ballistic movement) and at a slower comfortable speed (self-paced movement). Subjects were instructed to stop the movement as close as possible to the 
Table 1. Behavioral measurements (mean \pm SD)

\begin{tabular}{|c|c|c|c|c|c|c|}
\hline & \multicolumn{3}{|l|}{ Finger task } & \multicolumn{3}{|l|}{ Elbow task } \\
\hline & Self-paced & Ballistic & $p$ value & Self-paced & Ballistic & $p$ value \\
\hline Reaction time (ms) & $328.9 \pm 67.4$ & $224.8 \pm 48.4$ & $<0.001$ & $328.2 \pm 48.7$ & $233.3 \pm 58.3$ & $<0.001$ \\
\hline Movement amplitude (degrees) & $21.9 \pm 2.1$ & $26.4 \pm 4.4$ & 0.02 & $31.6 \pm 1.4$ & $36.9 \pm 2.8$ & 0.003 \\
\hline Maximal angular velocity (degrees/s) & $35.9 \pm 13.3$ & $349.5 \pm 105.3$ & $<0.001$ & $46.1 \pm 18.5$ & $258.3 \pm 40.3$ & $<0.001$ \\
\hline
\end{tabular}

Table 2. Stimulation parameters and MEP size (mean \pm SD)

\begin{tabular}{|c|c|c|c|c|c|c|}
\hline & \multicolumn{3}{|l|}{ Finger task } & \multicolumn{3}{|l|}{ Elbow task } \\
\hline & Self-paced & Ballistic & $p$ value & Self-paced & Ballistic & $p$ value \\
\hline \multicolumn{7}{|l|}{ Rest } \\
\hline TS (\% MSO) & $59.9 \pm 10.4$ & & & $78.6 \pm 12.7$ & & \\
\hline CS (\% MSO) & $61.7 \pm 9.3$ & & & $80.1 \pm 13.4$ & & \\
\hline Test MEP (mV) & $1.78 \pm 0.5$ & & & $0.46 \pm 0.3$ & & \\
\hline MEP elicited by CS (mV) & $1.88 \pm 1.2$ & & & $0.12 \pm 0.1$ & & \\
\hline \multicolumn{7}{|l|}{ Preparatory phase } \\
\hline TS (\% MSO) & $59.9 \pm 10.4$ & & & $78.6 \pm 12.7$ & & \\
\hline CS (\% MSO) & $61.7 \pm 9.3$ & & & $80.1 \pm 13.4$ & & \\
\hline Test MEP (mV) & $2.19 \pm 1.0$ & $2.22 \pm 1.3$ & 0.21 & $0.57 \pm 0.3$ & $0.71 \pm 0.3$ & 0.10 \\
\hline MEP elicited by CS (mV) & $1.64 \pm 1.1$ & $1.70 \pm 1.1$ & 0.35 & $0.18 \pm 0.1$ & $0.15 \pm 0.1$ & 0.24 \\
\hline \multicolumn{7}{|l|}{ Execution phase } \\
\hline \multicolumn{7}{|l|}{ Unadjusted } \\
\hline TS (\% MSO) & $45.5 \pm 14.6$ & & & $70.4 \pm 7.3$ & & \\
\hline CS (\% MSO) & $51.5 \pm 10.8$ & & & $90.9 \pm 9.1$ & & \\
\hline Test MEP (mV) & $3.00 \pm 1.2$ & $5.91 \pm 2.9$ & $<0.001$ & $2.02 \pm 1.5$ & $6.55 \pm 4.2$ & $<0.001$ \\
\hline MEP elicited by CS (mV) & $1.97 \pm 1.0$ & $2.26 \pm 1.3$ & 0.35 & $0.44 \pm 0.4$ & $0.44 \pm 0.4$ & 0.98 \\
\hline \multicolumn{7}{|l|}{ Adjusted } \\
\hline TS (\% MSO) & & $35.8 \pm 11.8$ & 0.21 & & $46.1 \pm 6.6$ & $<0.001$ \\
\hline CS (\% MSO) & & $51.5 \pm 10.8$ & & & $90.9 \pm 9.1$ & \\
\hline Test MEP (mV) & & $3.15 \pm 1.5$ & 0.81 & & $2.48 \pm 2.3$ & 0.51 \\
\hline MEP elicited by CS (mV) & & $1.88 \pm 0.9$ & 0.40 & & $0.41 \pm 0.4$ & 0.91 \\
\hline
\end{tabular}

Table 3. Ipsilateral silent period (mean \pm SD)

\begin{tabular}{|c|c|c|c|c|c|c|}
\hline & \multicolumn{3}{|l|}{ Finger task } & \multicolumn{3}{|l|}{ Elbow task } \\
\hline & Self-paced & Ballistic & $p$ value & Self-paced & Ballistic & $p$ value \\
\hline Latency (ms) & $33.4 \pm 4.4$ & $31.0 \pm 2.7$ & 0.11 & $28.6 \pm 3.7$ & $27.6 \pm 3.6$ & 0.48 \\
\hline Duration (ms) & $34.2 \pm 10.7$ & $33.9 \pm 11.0$ & 0.78 & $36.7 \pm 8.8$ & $37.4 \pm 11.5$ & 0.80 \\
\hline Normalized area (\%) & $52.8 \pm 14.9$ & $43.9 \pm 11.8$ & $<0.001$ & $75.2 \pm 13.1$ & $46.2 \pm 12.6$ & $<0.001$ \\
\hline
\end{tabular}

visual target and then return to the starting position. In an additional control experiment $(n=7)$, subjects were instructed to completely stop the movement in the ballistic task to better match performance strategies across tasks. Here, subjects held their movements on the target position for a few seconds until the visual target disappeared. A familiarization trial was completed at the beginning of each experiment to ensure that subjects were able to complete the task at the adequate speed. A total of $7.3 \pm 9.4 \%$ trials in which the mean rectified EMG signals were $>2$ SD of the mean resting EMG activity, measured $100 \mathrm{~ms}$ before the stimulus artifact, were excluded from further analysis.

\section{TMS}

Transcranial magnetic stimuli were delivered from a Magstim 200 stimulator (Magstim Company) through a figure-eight coil (loop diameter, 7 $\mathrm{cm}$; type number, 16342) with a monophasic current waveform. TMS was delivered to the optimal scalp position for activation of the left and right FDI and BB muscles. The scalp position for FDI and BB was determined with the coil held tangential to the scalp and the handle pointing backward and $45^{\circ}$ away from the midline. With this coil position, the current flowed in a posterior-medial direction and probably produced $\mathrm{D}$ and early I wave activation of corticospinal neurons (Sakai et al., 1997). During testing, the TMS coil was held to the head of the subject with a custom coil holder with the head held with straps against a headrest to restrict movements. TMS measurements included resting motor threshold (RMT), maximal motor evoked potential (MEP) size (MEP-max), paired-pulse IHI, and the iSP.
$R M T$ and $M E P-\max$

RMT (FDI, $44.9 \pm 7.7 \%$; BB, $63.7 \pm 10.7 \%$; $p<0.001$ ) was defined as the minimal stimulus intensity required to induce MEPs $>50 \mu \mathrm{V}$ peak-topeak amplitude in 5 of 10 consecutive trials in the relaxed FDI and BB muscles (Rothwell et al., 1999). The MEP-max was defined in all subjects at rest by increasing stimulus intensities in 5\% steps of maximal device output until the MEP amplitude did not show additional increase (MEP-max, FDI, $3.56 \pm 0.9 \mathrm{mV}$; BB, $0.83 \pm 0.3 \mathrm{mV} ; p<$ $0.001)$. At the beginning of each session, 20 trials without TMS were recorded to determine reaction time (RT) on each muscle tested during the different movement conditions. RT was defined as the time when mean rectified EMG signal was $>2$ SD of the mean resting EMG activity, measured $100 \mathrm{~ms}$ before the go signal (Table 1). Movement amplitude was measured as the angular displacement from the starting position to the peak angle (Table 1). To compare movement amplitude across tasks, the angular position of the target was subtracted from the maximal peak angle.

\section{Paired-pulse IHI}

IHI from the left to the right M1 was tested using a randomized conditioning-test design previously reported (Ferbert et al., 1992). IHI was tested at rest and in the preparatory and execution phases of selfpaced and ballistic index finger and elbow movements. Testing was completed at a conditioning-test interval of $40 \mathrm{~ms}$, the time between the conditioning stimulus (CS) and test stimulus (TS), which likely reflect activity from similar GABAergic neuronal populations tested with the iSP (see below, iSP; Chen et al., 2003). The CS was delivered to the optimal scalp position for activating the right FDI and BB muscles. A suprathreshold CS was set at an intensity that elicited $\sim 50 \%$ of each subject's maximal IHI at rest. This approach was used to ensure that during voluntary activity, we have the possibility to increase and/or decrease the magnitude of IHI (Soteropoulos and Perez, 2011). The TS was always delivered to the optimal scalp position for activation of the left FDI and BB muscles. The intensity of the TS was adjusted for each subject to elicit a test MEP of $\sim 50 \%$ of the MEP-max at rest 
A

FINGER TASK

Rest

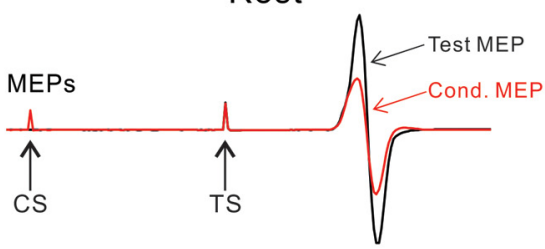

Self-paced

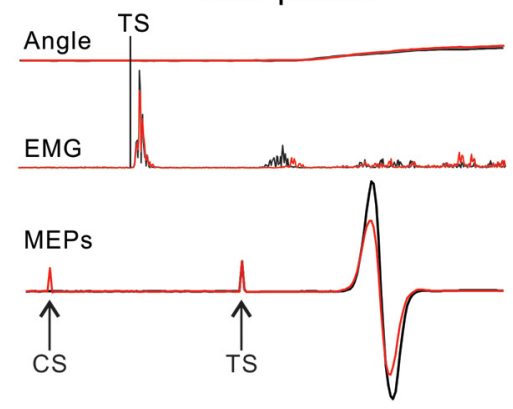

Ballistic
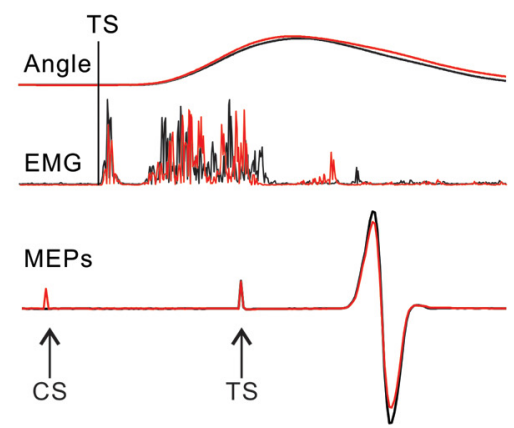

C

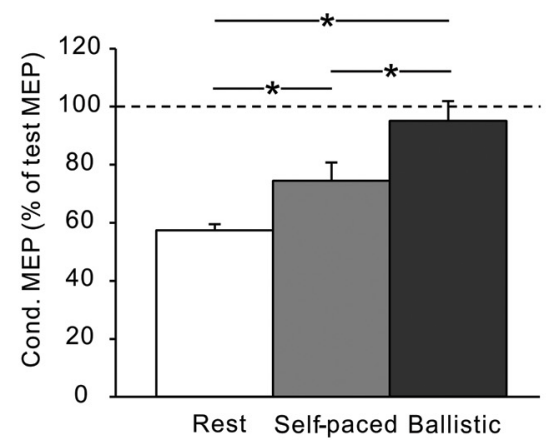

B

\section{ELBOW TASK}

\section{Rest}
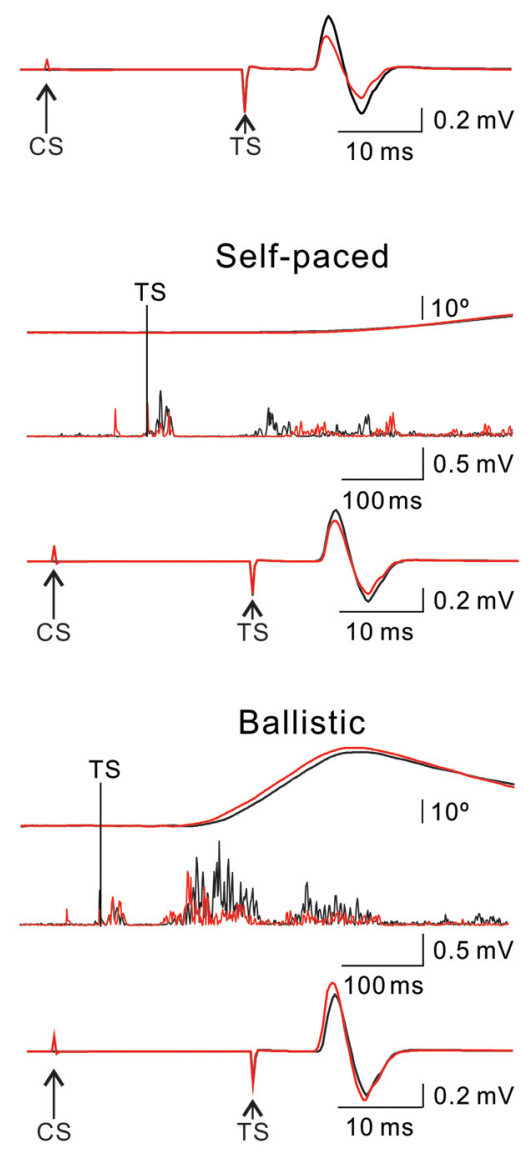

D

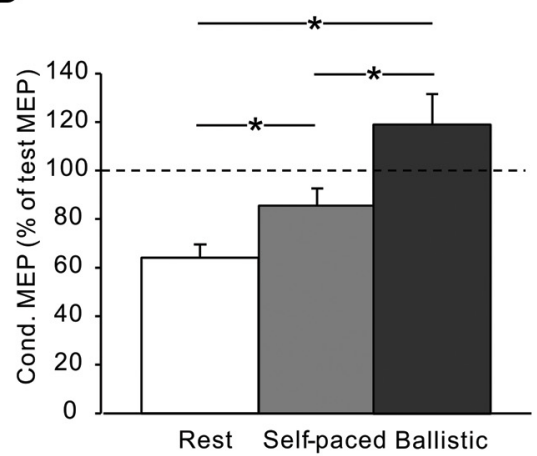

Figure 2. IHI at rest and during movement preparation. $A, B,|H|$ tested in the index finger $(\boldsymbol{A})$ and elbow $(\boldsymbol{B})$ tasks of a representative subject at rest (top traces) and during the preparatory phase of self-paced (middle traces) and ballistic (bottom traces) movements. The test and conditioned (Cond.) MEP are indicated by black and red arrows, respectively. During self-paced and ballistic movements, the traces above MEPs show the rectified EMG activity and angular displacement during each movement condition. Vertical lines show the time of the TS during IHI testing. Arrows indicate the time points at which the TS and CS are delivered. C, D, Group data (index finger task, $n=12$, C; elbow task, $n=8, \boldsymbol{D})$. The abscissa shows all conditions tested (rest, self-paced, and ballistic movements). The ordinate shows the magnitude of the conditioned MEP expressed as a percentage of thetest MEP. The horizontal dashed linerepresents the size of the test MEP. Note that IHI decreased during self-paced and ballistic index finger and elbow movements. Also the decrease in IHI was more pronounced during ballistic compared to self-paced movements in both motor tasks. Error bars indicate SES. ${ }^{*} p<0.05$.

(FDI, $50.0 \pm 8.3 \%$ of MEP-max; BB, $48.7 \pm 11.1 \%$ of MEP-max; $p=$ 0.28 ). Using the same CS and TS intensity, IHI was tested at rest and in the preparatory and execution phases of self-paced and ballistic movements.
Preparatory phase. To ensure that stimulation was given at a similar time in the preparatory phase of the movement, the TS was applied $\sim 90 \mathrm{~ms}$ (average, $87.3 \pm 16.2 \mathrm{~ms}$ ) before the shorter RT obtained during 20 consecutive self-paced and ballistic movements completed at the beginning of the experiment. Because at the beginning of testing, the size of the MEP elicited by the TS in the preparatory phase of self-paced movements increased compared to rest (Chen et al., 1998; Table 2), IHI was tested after familiarization with the task was completed. On average, the size of the MEP elicited by the TS was similar to the resting condition after $38.3 \pm 13.3$ trials. In addition, in a separate control experiment, IHI was also tested by adjusting the size of the test MEP to match the size at rest without the familiarization period (Table 2). The size of the MEP elicited by the TS applied $\sim 90 \mathrm{~ms}$ in the preparatory phase of ballistic movements was not increased (Chen et al., 1998); therefore, no adjustments were completed.

Execution phase. To ensure that stimulation was given at a similar time of the movement duration (self-paced, finger task, $49.7 \pm 3.3 \%$ of movement amplitude; elbow task, $51.6 \pm$ $4.0 \%$ of movement amplitude; $p=0.22$; ballistic, finger task, $4.6 \pm 2.6 \%$ of movement amplitude; elbow task, $3.8 \pm 2.5 \%$ of movement amplitude; $p=0.46$ ) and background EMG activity (self-paced, finger task, $8.5 \pm 4.6 \%$ of MVC; elbow task, $7.0 \pm 7.4 \%$ of MVC; $p=$ 0.22 ; ballistic, finger task, $31.9 \pm 15.7 \%$ of MVC; elbow task, $34.2 \pm 26.8 \%$ of MVC; $p=$ 0.75 ) during both motor tasks and at a similar time of the peak EMG burst duration across movement speeds (finger task, self-paced, $56.2 \pm 4.4 \%$ of peak EMG burst; ballistic, $54.9 \pm 11.9 \%$ of peak EMG burst; $p=0.7$; elbow task, self-paced, $59.1 \pm 12.6 \%$ of peak EMG burst; ballistic, $60.1 \pm 14.8 \%$ of peak EMG burst, $p=0.8$ ), the TS was applied $829.9 \pm 151.1 \mathrm{~ms}$ and $70.1 \pm 14.6 \mathrm{~ms}$ after the beginning of self-paced and ballistic movements, respectively. This also allowed us to applied stimulation during the middle part of the EMG burst in each task. Because the size of the MEP elicited by the TS in the execution phase of movements largely increased compared to rest, it was possible to test IHI by adjusting the size of the test MEP to match the resting condition only in the self-paced task (Table 2). Furthermore, since IHI was largely abolished in the execution phase of self-paced movements compared to rest, IHI was also tested by using a suprathreshold CS at an intensity that elicited a strong IHI during the execution phase to make further comparisons with responses obtained during ballistic movements. Here, the intensity of the TS was adjusted for each subject to elicit a test MEP of $\sim 50 \%$ of the MEP-max (FDI, $48.1 \pm 19.4 \%$ of MEP-max; BB, $51.6 \pm 19.1 \%$ of MEP$\max ; p=0.69)$. During this comparison, because the size of the MEP elicited by the TS increased during the execution phase of ballistic compared to selfpaced movements, IHI was tested by adjusting the size of the test MEP to match the size of the TS during self-paced movements 
(Table 2). In both phases of movement, IHI was calculated by expressing the size of the conditioned MEP as a percentage of the size of the test MEP [ (conditioned MEP $\times 100) /$ (test MEP)]. A total of 20 test MEPs and 20 conditioned MEPs were tested in each condition.

iSP

As another measurement of transcallosal inhibition, the iSP was examined in the left FDI and $\mathrm{BB}$ muscles in the execution phase of self-paced and ballistic movements. In each session, the intensity of TMS was adjusted in each subject to produce a visible iSP without a previous facilitation. The iSP was more frequently observed in the FDI than BB during self-paced movements. TMS was applied at the same intensity during self-paced and ballistic movements (FDI, $127.6 \pm 4.1 \%$ of RMT; BB, $126.2 \pm 6.3 \%$ of RMT; $p=0.53$ ). A total of 40 trials with TMS and 40 trials without TMS were randomly tested on each movement condition. The iSP was measured following a previously standardize method (Trompetto et al., 2004; Tazoe et al., 2013). iSP onset was defined as the time-point when the EMG activity dropped below the mean (minimal duration of $10 \mathrm{~ms}$ ), and the end of the iSP as the time-point when the EMG activity returned through this level (Table 3 ). The area of the iSP was calculated using the following formula: [iSP area = (mean EMG burst $) \times($ iSP duration $)-($ au_iSP $)$ ], where mean EMG burst is the average of the mean EMG burst in the iSP period on trials without TMS, and au_iSP is the area under the rectified iSP. The iSP area was normalized against the level of contraction [iSP area normalized to contraction $=$ iSP area/(area under mean EMG burst on trials without TMS); Table 3]. TMS was applied at the same time described above for the TS during IHI testing in both movement conditions. Because the magnitude of background EMG activity during the execution phase increased during ballistic compared to self-paced movements, the iSP was also tested at increasing levels of isometric voluntary contractions $(5,10,20,30,40$, and $50 \%$ of MVC). During these trials, the iSP onset, offset, and area were determined using the same parameters described above.

Data analysis

Normal distribution was tested using the Shapiro-Wilk test, and homogeneity of variances using the Levene median test. Repeatedmeasures ANOVAs were performed to determine the effect of movement condition (rest, self-paced, ballistic) and task (finger task, elbow task) in the preparatory and execution phases on IHI. The same analysis was completed to compare RMT, intensities for CS and TS, MEP-max, and mean rectified EMG activity across conditions. Repeated-measures ANOVAs were also performed to examine the effect of movement speed (selfpaced, ballistic) and task (finger task, elbow task) in the preparatory phase on IHI and in the execution phase on the iSP area. The same analysis was performed to examine the effect of MVC level $(5,10,20$, 30,40 , and $50 \%$ of MVC) on the iSP area. A post hoc Holm-Sidak test was used to test for significant comparisons. Pearson correlation analysis was used as needed. Significance was set at $p<0.05$. Group data are presented as the means \pm SD in the text.

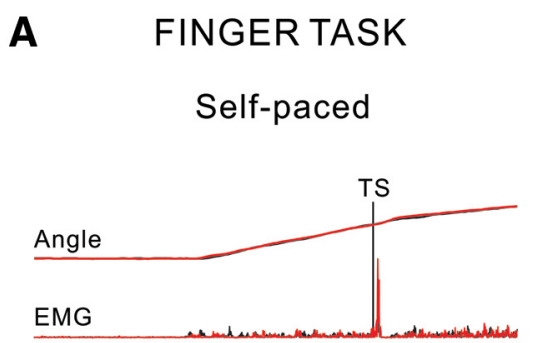

B ELBOW TASK
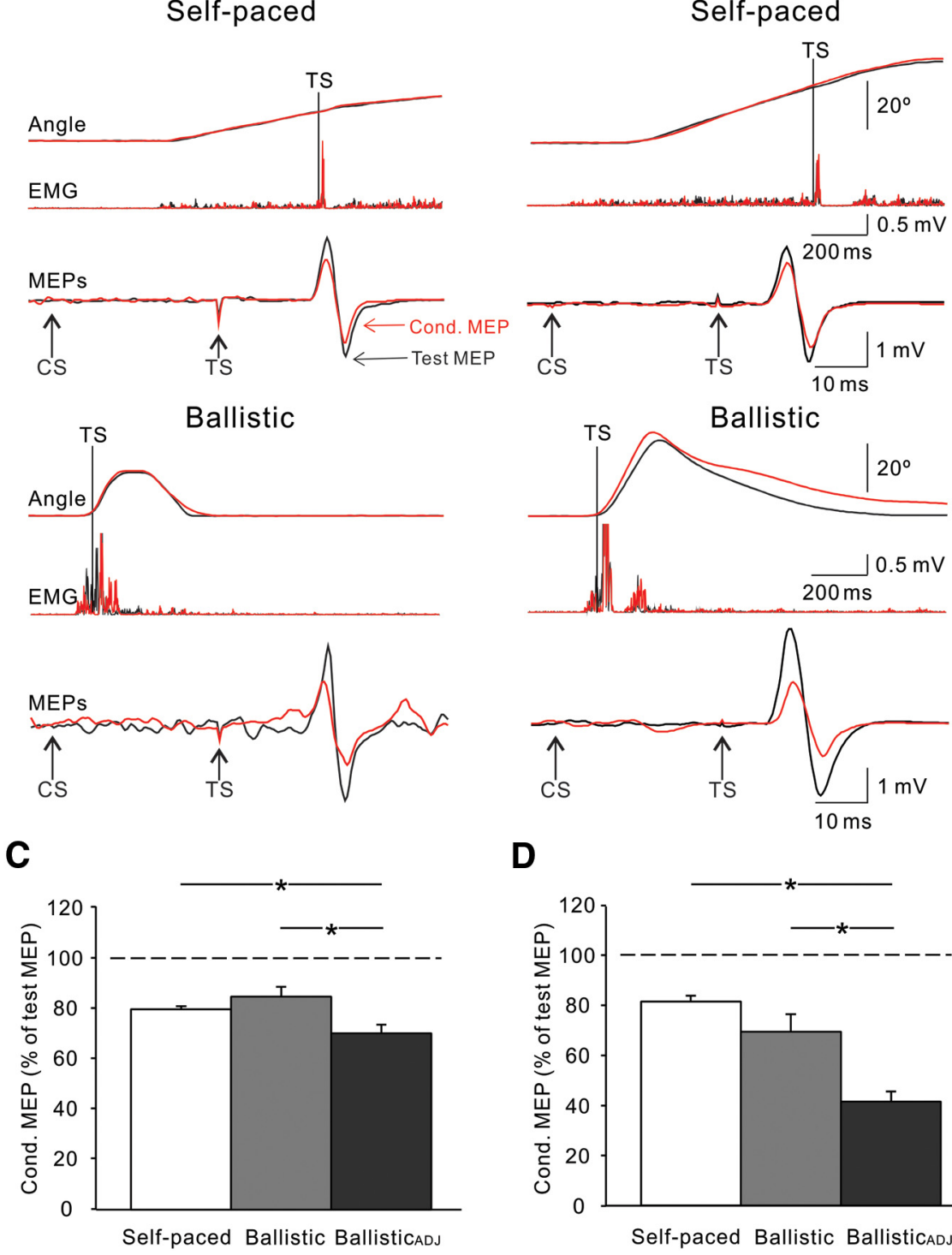

D

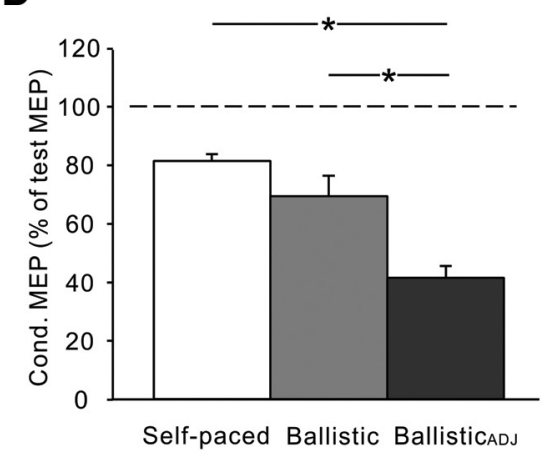

Figure 3. IHI during movement execution. $\boldsymbol{A}, \boldsymbol{B}, \mathrm{IHI}$ tested in the index finger $(\boldsymbol{A})$ and elbow $(\boldsymbol{B})$ tasks of a representative subject during the execution phase of self-paced (top traces) and ballistic (bottom traces) movements. The test and conditioned (Cond.) MEP are indicated by black and red arrows, respectively. Traces above MEPs show the rectified EMG activity and angular displacement during each movement condition. Vertical lines show the time of the TS during IHI testing. Arrows indicate the time points at which the TS and $(S$ are delivered. $\boldsymbol{C}, \boldsymbol{D}$, Group data (index finger task, $n=11, \boldsymbol{C}$; elbow task, $n=8, \boldsymbol{D})$. The abscissa shows all conditions tested (self-paced, ballistic, and ballistic ADJ $_{\text {) }}$. The ordinate shows the magnitude of the conditioned MEP expressed as a percentage of the test MEP. The horizontal dashed line represents the size of the test MEP. Note the decrease in IHI during ballistic $_{A D J}$ index finger and elbow movements. No changes in IHI were observed in the ballistic condition compared to self-paced movements in the unadjusted condition. Error bars indicate SEs. ${ }^{*} p<0.05$.

\section{Results}

IHI

Figure 2 illustrates raw data from IHI measured in the FDI and $\mathrm{BB}$ muscles at rest and in the preparatory phase of self-paced and ballistic movements. Note that IHI decreased during self-paced and ballistic index finger and elbow movements compared to rest, but the decrease in IHI was larger during ballistic than selfpaced movements.

Repeated-measures ANOVA showed a significant effect of movement condition $\left(F_{(2,36)}=41.7, p<0.001\right)$, but not task $\left(F_{(1,18)}=3.1, p=0.09\right)$ nor in their interaction $\left(F_{(2,36)}=1.6, p=\right.$ 0.21 ; Fig. 2) on IHI measured in the preparatory phase. Post hoc 
A

FINGER TASK

\section{Self-paced}
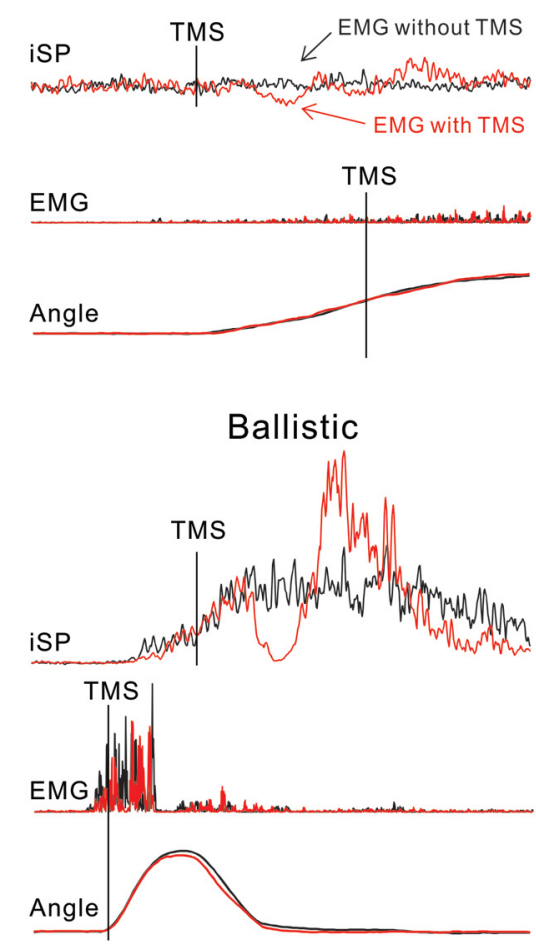

C

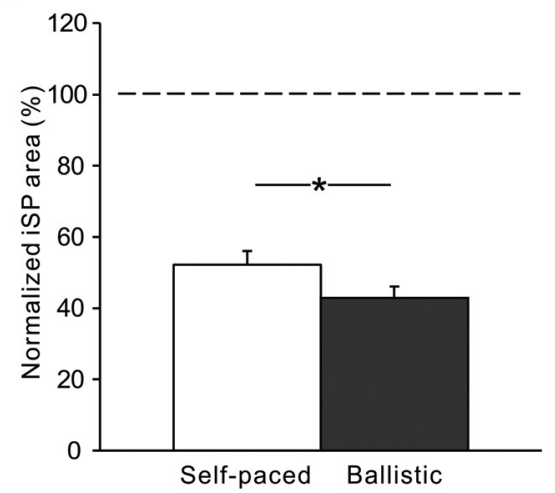

B

\section{ELBOW TASK}

Self-paced

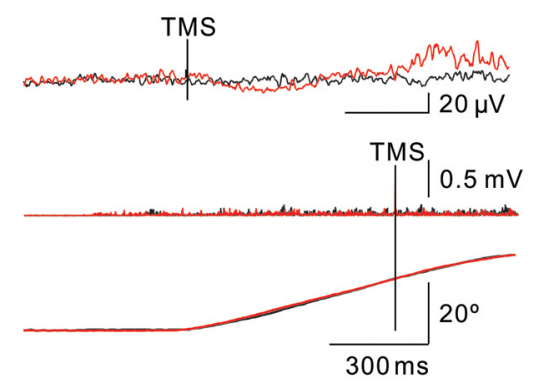

Ballistic

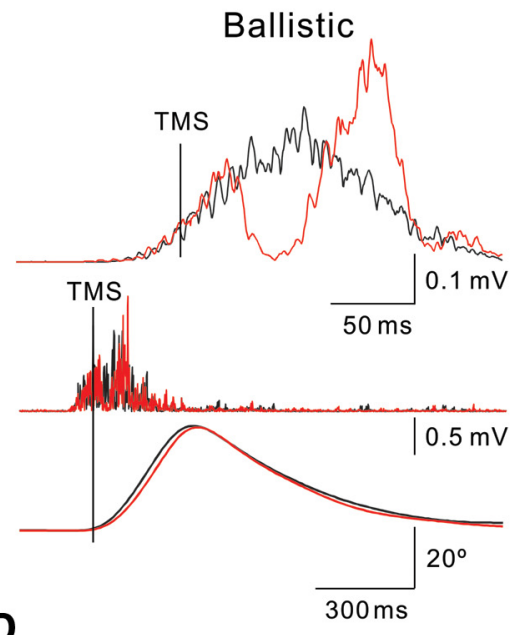

D

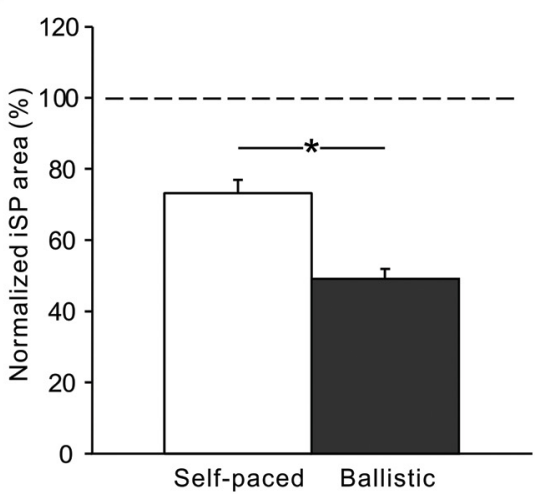

Figure 4. iSP during movement execution. $A, B$, Raw traces showing rectified EMG activity in representative subjects during iSP testing in self-paced and ballistic index finger $(\boldsymbol{A})$ and elbow flexion $(\boldsymbol{B})$ movements. Traces show the average 40 trials tested with (red traces) and without (black traces) TMS. Traces below iSPs show the rectified EMG activity and angular displacement during each movement condition. Vertical solid lines show the time of TMS during testing. C, D, Group data (index finger task, $n=14, \boldsymbol{C}$; elbow task, $n=11, \boldsymbol{D})$. The abscissa shows all conditions tested (self-paced and ballistic). The ordinate shows the normalized iSP area. Note the increase in the iSP during ballistic index finger and elbow movements compared to self-paced movements. Error bars indicate SEs. ${ }^{*} p<0.05$.

testing showed that IHI was decreased during self-paced and ballistic movements compared to rest in the index finger (rest, $57.5 \pm 7.1 \%$; self-paced, $74.4 \pm 22.0 \% ; p=0.01$; ballistic, $95.0 \pm$ $23.6 \%$; $p<0.001$; Figure $2 C$ ) and elbow (rest, $64.2 \pm 15.6 \%$; self-paced, $85.7 \pm 20.0 \% ; p=0.01$; ballistic, $119.3 \pm 35.6 \% ; p<$ 0.001 ; Figure $2 D$ ) tasks. We found that IHI was decreased to a larger extent during ballistic compared to self-paced movements in the finger $(p<0.001)$ and elbow $(p<0.001)$ tasks. Mean background rectified EMG activity in the FDI and BB in the preparatory phase remained similar across conditions $\left(F_{(2,36)}=0.7, p=0.52\right)$ and tasks $\left(F_{(1,18)}=0.5, p=0.51\right)$.

Because MEP size increased during the preparatory phase of self-paced movements in trials without familiarization, IHI was also tested by adjusting the size of the MEPs evoked by the TS to match the resting values. Similar to our previous findings, we found a significant effect of movement condition $\left(F_{(2,30)}=119.8, p<0.001\right)$ on IHI. During self-paced movements, IHI was decreased compared to rest in the finger (rest, $44.8 \pm 11.1 \%$; self-paced, $55.4 \pm 11.9 \%$; $p=0.02$; ballistic, $87.4 \pm 11.8 \%$; $p<0.001$ ) and elbow (rest, $61.0 \pm 111.7 \%$; self-paced, $94.6 \pm 9.6 \% ; p<0.001$; ballistic, $125.4 \pm$ $17.0 \% ; p<0.001)$ tasks. The decrease in IHI was larger during ballistic compared to selfpaced movements in the finger $(p<0.001)$ and elbow $(p<0.001)$ tasks. Together, these results show that in the preparatory phase of slow and fast movements the magnitude of IHI is decreased compared to rest. However, the decrease in IHI is larger during fast compared to slow index finger and elbow movements.

Figure 3 illustrates raw data from IHI measured in the FDI and BB muscles during the execution phase of movements. In contrast to the results in the preparatory phase, we found that IHI increased during ballistic compared to a self-paced movement in both motor tasks. Repeatedmeasures ANOVA showed significant effects of movement speed $\left(F_{(2,36)}=\right.$ $35.5, p<0.001)$, task $\left(F_{(1,18)}=15.6, p<\right.$ $0.001)$, and their interaction $\left(F_{(2,36)}=\right.$ $13.1, p<0.001)$ on IHI measured in the execution phase. Post hoc testing showed that adjusted IHI (ballistic ADI $_{\text {}}$ ) was increased during ballistic compared to self-paced movements in the finger (ballisti$\mathrm{c}_{\mathrm{ADJ}}, 69.3 \pm 10.6 \%$; self-paced, $79.6 \pm 3.9 \%$; $p=0.02$; Figure $3 C$ ) and elbow (ballistic $\mathrm{ADJ}_{\mathrm{AD}}$, $41.3 \pm 11.4 \%$; self-paced, $81.3 \pm 6.6 \%$; $p<$ 0.001 ; Figure $3 D$ ) tasks. IHI was unchanged during ballistic compared to self-paced movement in the unadjusted IHI testing in the index finger $(p=0.33)$ and elbow $(p=$ 0.27 ) tasks. Here, the size of MEP elicited by the TS during the ballistic tasks was twofold larger than in the self-paced task (Table 2). During voluntary contraction, mean background rectified EMG activity in the FDI and BB muscles remained similar across tasks $\left(F_{(1,18)}=0.20, p=0.66\right)$.

The direct comparison of IHI measured in the execution phase of movements and at rest was difficult to achieve due to technical reasons. Below we present the results and the technical challenges, which may contribute to the explanation of some of previous finding reporting a decrease in IHI during tonic voluntary activity compared to rest. Repeated-measures ANOVA showed a significant effect of task $\left(F_{(2,36)}=33.5, p<0.001\right)$, but 
not movement condition $\left(F_{(1,18)}=0.4, p=0.54\right)$ nor in their interaction $\left(F_{(2,36)}=1.77, p=0.19\right)$ on IHI measured in the execution phase. Post hoc testing showed that IHI was decreased during the execution phase of self-paced and ballistic movements compared to rest in the finger (rest, $57.5 \pm 7.1 \%$; self-paced, $90.8 \pm 18.3 \% ; p<0.001$; ballistic, $98.6 \pm 14.4 \% ; p<0.001)$ and elbow (rest, $62.2 \pm 15.6 \%$; self-paced, $82.1 \pm 19.5 \%$; $p=0.01$; ballistic, $92.4 \pm 10.0 \%$; $p<0.001)$ tasks. Adjusted IHI was unchanged during the execution phase compared to rest during self-paced index finger $(p=0.73)$ and elbow $(p=0.59)$ movements. Importantly, we found that when IHI was tested during voluntary activity, and depending on the stimulus intensity, the CS elicited an iSP for which rebound was present after the stimulation (self-paced, FDI, $47.2 \pm 16.9 \mathrm{~ms} ; \mathrm{BB}, 55.5 \pm 30.3 \mathrm{~ms}$; ballistic, FDI, $53.2 \pm 12.9 \mathrm{~ms}$; BB, $66.3 \pm 20.3 \mathrm{~ms}$ ). This rebound was present at the same time the conditioned MEP for IHI was tested (self-paced, FDI, $65.2 \pm 11.0 \mathrm{~ms} ; \mathrm{BB}, 65.8 \pm 12.8 \mathrm{~ms}$; ballistic, FDI, $64.8 \pm 9.0 \mathrm{~ms}$; BB, $67.7 \pm 10.6 \mathrm{~ms}$ ). This result highlights the need to consider these methodological issues during testing of IHI outcomes during voluntary activity (for more details, see Discussion).

In summary, IHI tested in the preparatory phase was decreased during slow and fast movements compared to rest, and this decrease was more pronounced during fast movements. In contrast, IHI tested in the execution phase was increased during fast compared to slow movements. Together, our results demonstrate a differential speed-dependent contribution of transcallosal pathways to ipsilateral movements.

\section{iSP}

Figure 4 illustrates examples of the iSP elicited in the FDI and BB muscles during self-paced and ballistic movements in a representative participant. Note that the area of the iSP was increased during ballistic compared to self-paced movement in the index finger and elbow tasks.

Repeated-measures ANOVA showed significant effects of movement speed $\left(F_{(1,23)}=35.6, p<0.001\right)$, task $\left(F_{(1,23)}=8.4\right.$, $p=0.008)$, and their interaction $\left(F_{(1,23)}=10.0, p=0.004\right)$ on the iSP area. Post hoc testing showed that the iSP area was increased during ballistic index finger (self-paced, $52.8 \pm 14.9 \%$; ballistic, $43.9 \pm 11.8 \% ; p<0.001$ ) and elbow (self-paced, $75.3 \pm 13.1 \%$; ballistic, $46.2 \pm 12.6 \%$; $p=0.002$ ) compared to self-paced movements. When both tasks were compared, we found that the iSP was increased to a larger extent during ballistic compared to selfpaced movements in the elbow compared to the finger $(p=0.01)$ task. During voluntary contraction, mean background rectified EMG activity in the FDI and BB remained similar across tasks $\left(F_{(1,23)}=0.28, p=0.60\right)$. The iSP area was increased during the ballistic index finger (self-paced, $56.6 \pm 15.1 \%$; ballistic, $50.2 \pm$ $10.2 \% ; p=0.04$ ) and elbow (self-paced, $76.3 \pm 15.2 \%$; ballistic, $47.7 \pm 10.6 \% ; p=0.03)$ tasks, where subjects were instructed to completely stop the movement on the target position, compared to the self-paced task. Since the amount of EMG background activity increased during ballistic compared to self-paced movements, the iSP was also tested by increasing the levels of EMG activity in the index finger task (Fig. 5). We found no effect of MVC level on the iSP area in the FDI $\left(F_{(5,4)}=0.5, p=0.8\right)$ muscle. Overall, these results in agreement with our IHI measurements show that during movement execution, the magnitude of transcallosal inhibition was larger during fast compared to slow index finger and elbow movements.
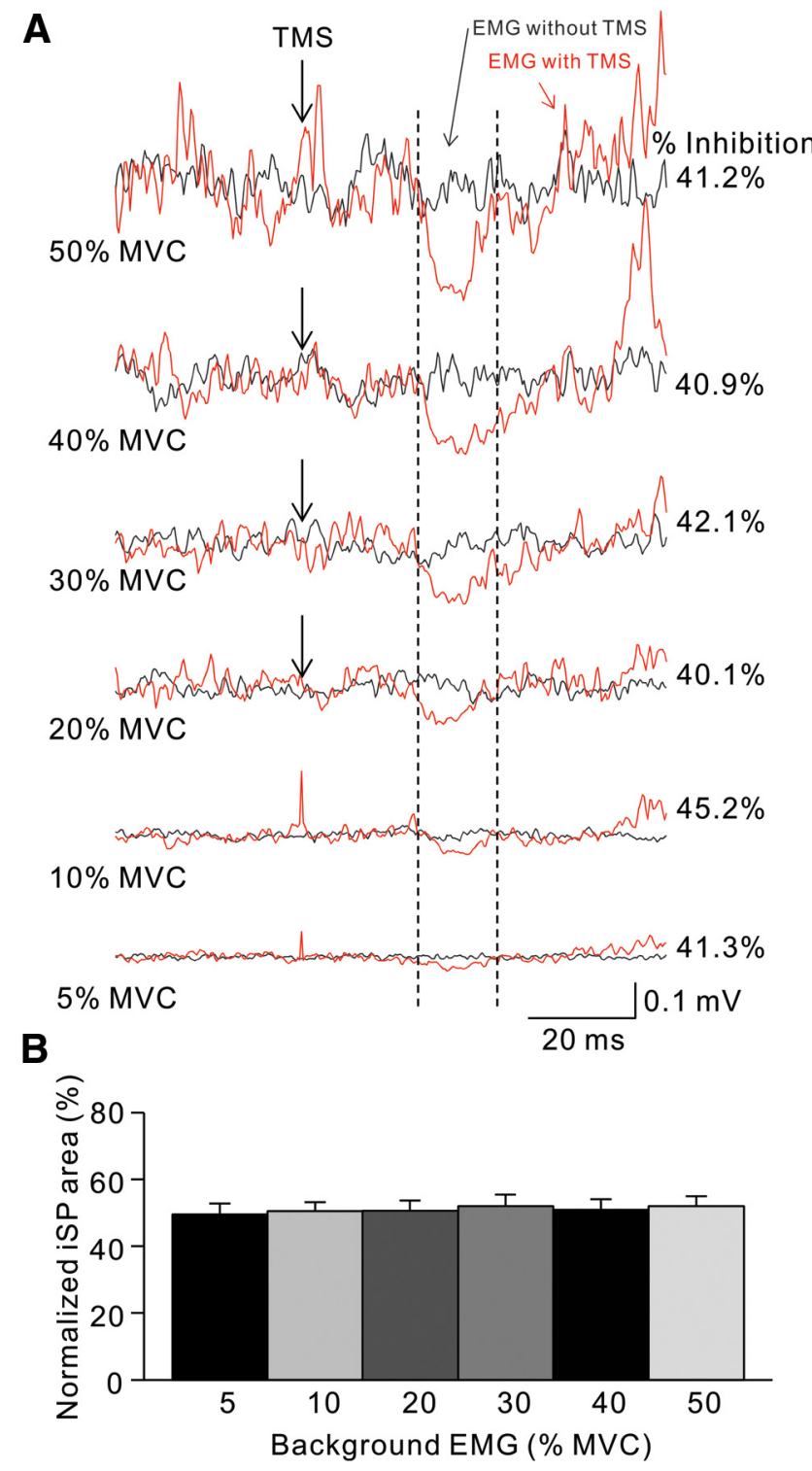

Figure 5. iSP during isometric index finger abduction. $\boldsymbol{A}$, Raw traces showing rectified EMG activity in representative subjects during iSP testing at increasing levels of isometric MVC into index abduction. Traces show the average 40 trials tested with (red traces) and without (black traces) TMS. Arrows show the time of TMS during testing, and vertical dashed lines show the onset and offset of the iSP. $\boldsymbol{B}$, Group data $(n=9)$. The abscissa shows all conditions tested ( 5 , $10,20,30,40$, and $50 \%$ of MVC). The ordinate shows the normalized iSP area. Note that the iSP area remained unchanged during increasing levels of isometric index finger abduction. Error bars indicate SEs. * $p<0.05$.

\section{Correlations analysis}

A negative correlation was found between the magnitude of IHI measured in the preparatory phase of ballistic movements and RT $(r=-0.60, p=0.006$; Fig. $6 B)$. Here, note that individuals with larger decreases in IHI were those who performed movements at faster speeds. The RT during self-paced movements did not significantly correlate with the magnitude of IHI measured during the preparatory phase $(r=-0.37, p=0.11$; Fig. $6 A)$. The area of the iSP in the execution phase of ballistic movements was positively correlated with the movement amplitude $(r=0.52$, $p=0.008$; Fig. $6 D$ ). Note that here individuals with stronger suppression of EMG activity were those who performed movements of smaller amplitudes. We did not find a significant correlation between the area of iSP in the execution phase of self-paced 
A
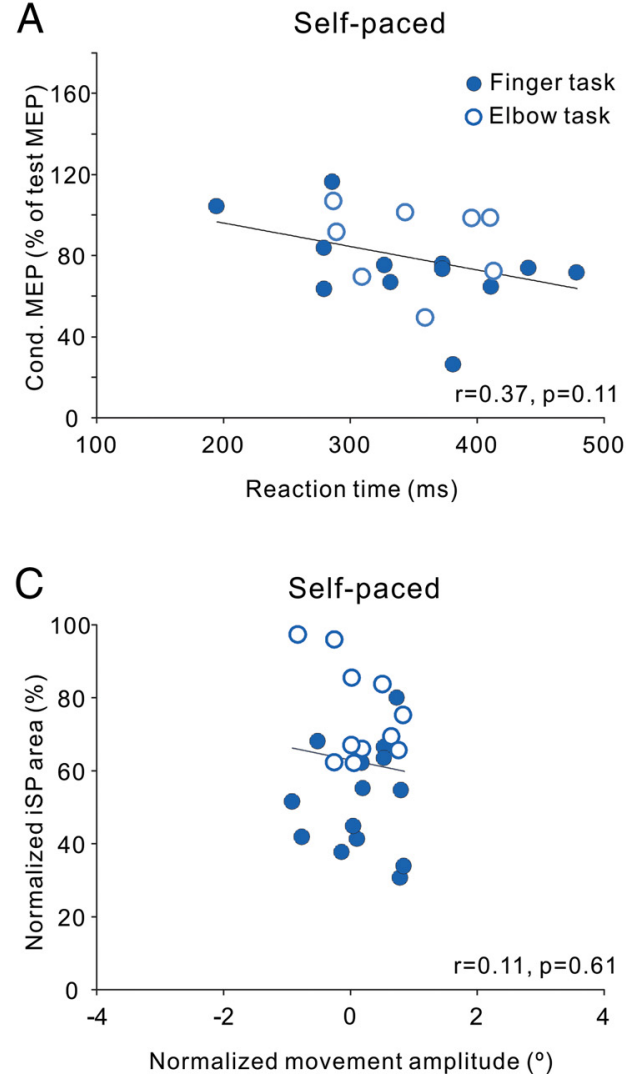

B
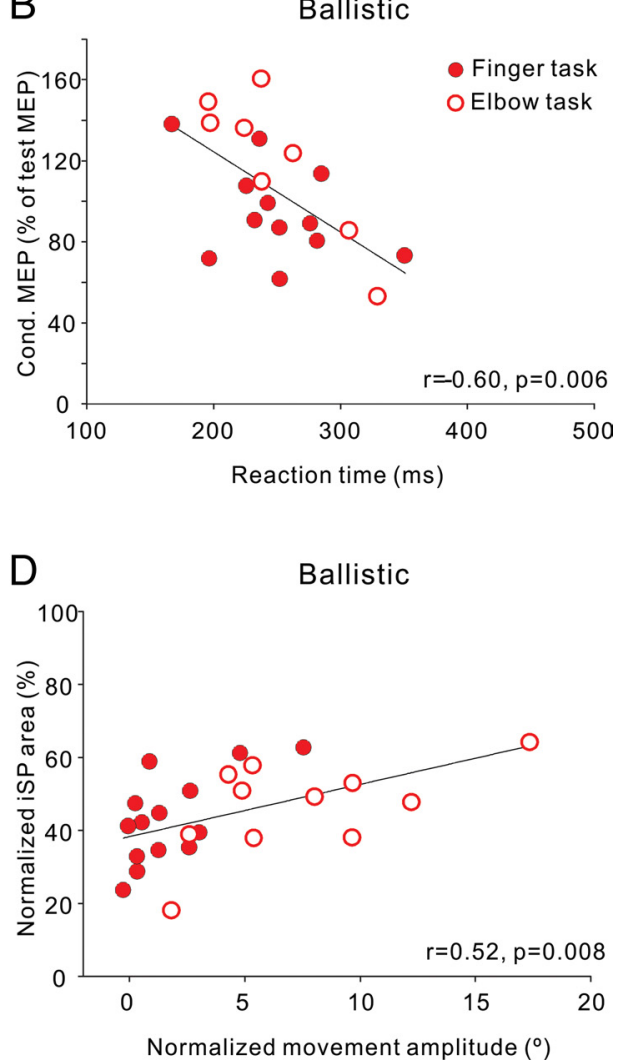

Figure 6. Correlation between transcallosal inhibition and movement variables. Top graphs show a correlation analysis between the magnitude of IHI in the preparatory phase of self-paced ( $\boldsymbol{A}$ ) and ballistic $(\boldsymbol{B})$ index finger and elbow tasks. The abscissa shows RTs in milliseconds. The ordinate shows the magnitude of the conditioned MEP expressed as a percentage of the test MEP. Note that there was a negative correlation between the magnitude of IHI and RT in the ballistic but not self-paced movements. Here, individuals with larger decreases in IHI were those who performed movements at faster speeds. Lower graphs show a correlation analysis between the magnitude of the iSP in the execution phase of self-paced $(\boldsymbol{C})$ and ballistic $(\boldsymbol{D})$ movements and the movement amplitude in the index finger and elbow tasks. The abscissa shows the normalized movement amplitude in degrees. The ordinate shows the normalized iSP area. Note that there was a positive correlation between the magnitude of the iSP and the movement amplitude during ballistic but not self-paced movements. Thus, subjects with stronger suppression of EMG activity were those who performed movements of smaller amplitudes. Error bars indicate SEs. ${ }^{*} p<0.05$.

movements and the movement amplitude $(r=-0.11, p=0.61$; Fig. $6 C)$.

\section{Discussion}

We demonstrate a speed-dependent contribution of transcallosal inhibition to ipsilateral movements in intact humans. First, we found that IHI decreases in the preparatory phase of self-paced and ballistic index finger and elbow movements compared to rest; the decrease in IHI was larger during ballistic than self-paced movements. Second, IHI and the iSP increased in the execution phase of ballistic compared to self-paced movements. Transcallosal inhibition was negatively correlated with reaction times in the preparatory phase and positively correlated with movement amplitude in the execution phase of ballistic movements. Our results show a differential contribution of activity in transcallosal pathways to discrete times of ipsilateral movements of increasing speed.

\section{Transcallosal inhibition in the preparatory phase of} ipsilateral movements of different speeds

Several studies have proposed that the functional role for transcallosal inhibition targeting the ipsilateral resting limb during voluntary activation of the contralateral side is to suppress unwanted EMG activity (Cincotta and Ziemann, 2008; Hübers et al., 2008; Giovannelli et al., 2009; Beaulé et al., 2012). Much less is known about the role of transcallosal inhibition from a resting to a voluntary active limb (Perez, 2012). Indeed, it is likely that this contribution will be different since during unilateral movements transcallosal inhibition toward the active limb may be involve in controlling aspects of a voluntary movement. We provide two important novel findings. First, we demonstrate that the contribution of transcallosal inhibitory pathways to the ipsilateral movements is dependent on the speed of a movement. We found that $\sim 90$ ms before movement onset, IHI decreases during selfpaced and ballistic index finger and elbow movements compared to rest. This is in agreement with previous evidence showing that during the preparatory phase of ballistic movements IHI targeting the ipsilateral limb decreases compared to rest (Murase et al., 2004; Duque et al., 2005; Liuzzi et al., 2010). Previous studies demonstrated that interhemispheric sharing during a motor task modulates the speed of upcoming movements (Guiard and Requin, 1977). A widespread disinhibitory effect during the preparation of movements has been observed in animal studies using direct recordings of motor cortical cells (Riehle and Requin, 1989; Churchland et al., 2006) and in human studies by measuring reaction times and physiological measurements (Coles et al., 1988; Chen et al., 1998; Leocani et al., 2000), including activity of other intracortical inhibitory circuits (Reynolds and Ashby, 1999; Sinclair and Hammond, 2008; Heise et al., 2010). Thus, our findings open the possibility that, as in other motor cortical circuits, a widespread disinhibitory effect also takes place in transcallosal inhibitory pathways before movement initiation. Second, we 
found that the decrease in IHI was larger during ballistic compared to self-paced movements. Data from studies in animals (Ganguly et al., 2009) and humans (Chen et al., 1997; Duque et al., 2005; Davare et al., 2007) suggest that transcallosal pathways contribute to kinematics parameters of ipsilateral arm movements. Our data indicate that the magnitude of the IHI contribution to ipsilateral movements change with movement speed. This agrees with evidence demonstrating that during voluntary activity the speed of a movements act as a multiplier for the modulation of motor cortical cells (Moran and Schwartz, 1999). This is also supported by the negative correlation found between IHI at fast speeds and reaction times. An interesting question is how this process might occur. Since preparatory activity is predictive of reaction time and movement variability (Bastian et al., 2003; Churchland and Shenoy, 2007), decreases in IHI at this time may represent an adaptive mechanism to shape a future motor strategy. It has been shown that movement parameters, including movement speed, were specified previously and have a clear impact on a motor plan (Churchland et al., 2006).

\section{Transcallosal inhibition in the execution phase of ipsilateral movements of different speeds}

We found that the iSP and IHI measured during movement execution were increased during ballistic compared to self-paced index finger and elbow movements. This agrees with previous evidence suggesting that the iSP and IHI reflect changes in similar neuronal mechanisms (Ferbert et al., 1992; Chen et al., 2003). The iSP is thought to be mediated by axons passing through the corpus callosum (Meyer et al., 1995; Boroojerdi et al., 1996). The cortical origin of the inhibition tested during IHI was provided by showing a suppression of the later indirect waves (I-waves) in recordings of descending volleys with epidural electrodes (Di Lazzaro et al., 1999) and supported by studies in patients (Meyer et al., 1995; Boroojerdi et al., 1996). Animal studies have shown that callosal neurons in awake primates increase their firing rates during ballistic compared to slower components of an arm motor task (Soteropoulos and Baker, 2007). Thus, we speculate that higher activity of callosal neurons during rapid movements may contribute to increased transmission in the transcallosal pathway.

Our data indicate that during the execution phase, as in the preparatory phase, transcallosal inhibition also has a functional contribution to rapid ipsilateral movements. This is supported by the positive correlation found between the magnitude of iSP at fast speeds and movement amplitude. Interestingly, subjects who reached the target position earlier showed larger iSPs. Since the iSP involves the removal of voluntary EMG activity, it is plausible that larger removal of EMG activity contributes to preventing movement overshoots from the target position when the speed is high. Moreover, the iSP area was also increased in the ballistic task compared to the self-paced task when subjects were instructed to completely stop the movement for a few seconds in the target position. This is also in agreement with previous physiological (Coxon et al., 2006; Duque et al., 2010) and modeling (Verbruggen and Logan, 2009; Noorani et al., 2011) studies proposing that increases in inhibitory processes contribute to stop fast movements. The lack of correlation between IHI at fast speeds and movement amplitude may be related to the nature of this measurement. During voluntary movement, motoneurons and corticospinal axons likely show a nonlinear relationship between "excitability" and their level of activity (Matthews, 1999), and this applies to MEPs tested during voluntary contractions (Devanne et al., 1997).

\section{Methodological considerations}

As expected, increases in the speed of index finger and elbow movements resulted in increments in the recruitment of EMG activity. Previous evidence showed that larger EMG activity exerted during a unilateral voluntary contraction results in enhanced activity in the ipsilateral motor cortex (Stedman et al., 1998; Muellbacher et al., 2000; Hortobágyi et al., 2003; Perez and Cohen, 2008; Bunday and Perez, 2012), and increasing corticospinal excitability results in more pronounced IHI targeting the ipsilateral limb (Lee et al., 2007). Although in our study EMG activity was increased during ballistic compared to self-paced movements, we found that the iSP area was similar at increasing levels of isometric EMG activity, making it less likely that this factor affected our results.

Another important consideration is the comparison of transcallosal inhibition during voluntary activity and rest. Similar to previous studies, we found that IHI tested during voluntary activity was decreased compared to that during rest (Gerloff et al., 1998; Chen et al., 2003; Nelson et al., 2009). However, our data also indicated that this disinhibitory effect is likely influenced by the aftereffects of the conditioning stimulus. By using a conditioning stimulus intensity that elicited robust IHI at rest, the same conditioning stimulus elicited an iSP during voluntary contraction for which rebound was present at the time that the conditioned MEP for IHI was measured. These and our previous findings (Perez and Cohen, 2008; Yedimenko and Perez, 2010) suggest that, for comparisons, examination of IHI during voluntary activity needs to take into consideration methodological aspects that are modulated by the ongoing voluntary activity. Furthermore, IHI and iSP are indirect measures of transcallosal activity that can be influenced by stimulation parameters (Ferbert et al., 1992; Perez and Cohen, 2008). In our study, stimulation parameters were maintained similar across the finger and elbow; therefore, it is unlikely that these aspects contributed to our findings. Thus, altogether, our results demonstrate a timeand speed-specific contribution of transcallosal pathways to ipsilateral movements.

\section{Functional significance}

Most of our daily tasks involve continuous changes in movement speed. An intriguing question is how transcallosal inhibition may have a differential role during the same ongoing voluntary task at events taking place at short time intervals. In animals, the firing rate of callosal cells during movements, even fast movements, is low (Soteropoulos and Baker, 2007). It has been proposed that activity of callosal cells may enable signaling for the existence of a discrete behavioral event, but not to encode continuous variables during movement (Soteropoulos and Baker, 2007). We argue that this role allows transcallosal inhibition to differentially contribute to the preparatory and execution phases of rapid movements. The ability to initiate and stop movements is affected in a number of motor disorders (Lemay et al., 2008; Cameron et al., 2010; Thorns et al., 2010), opening the possibility that our results impact voluntary output in clinical deficits.

\section{References}

Bastian A, Schöner G, Riehle A (2003) Preshaping and continuous evolution of motor cortical representations during movement preparation. Eur J Neurosci 18:2047-2058. CrossRef Medline

Beaulé V, Tremblay S, Théoret H (2012) Interhemispheric control of unilateral movement. Neural Plast 627816. Medline

Boroojerdi B, Diefenbach K, Ferbert A (1996) Transcallosal inhibition in cortical and subcortical cerebral vascular lesions. J Neurol Sci 144:160 170. CrossRef Medline 
Bunday KL, Perez MA (2012) Impaired crossed facilitation of the corticospinal pathway after cervical spinal cord injury. J Neurophysiol 107:29012911. CrossRef Medline

Cameron D, Murphy A, Morris ME, Raghav S, Iansek R (2010) Planned stopping in people with Parkinson. Parkinsonism Relat Disord 16:191196. CrossRef Medline

Chen R, Gerloff C, Hallett M, Cohen LG (1997) Involvement of the ipsilateral motor cortex in finger movements of different complexities. Ann Neurol 41:247-254. CrossRef Medline

Chen R, Yaseen Z, Cohen LG, Hallett M (1998) Time course of corticospinal excitability in reaction time and self-paced movements. Ann Neurol 44: 317-325. CrossRef Medline

Chen R, Yung D, Li JY (2003) Organization of ipsilateral excitatory and inhibitory pathways in the human motor cortex. J Neurophysiol 89: 1256-1264. Medline

Churchland MM, Shenoy KV (2007) Delay of movement caused by disruption of cortical preparatory activity. J Neurophysiol 97:348-359. CrossRef Medline

Churchland MM, Santhanam G, Shenoy KV (2006) Preparatory activity in premotor and motor cortex reflects the speed of the upcoming reach. J Neurophysiol 96:3130-3146. CrossRef Medline

Cincotta M, Ziemann U (2008) Neurophysiology of unimanual motor control and mirror movements. Clin Neurophysiol 119:744-762. CrossRef Medline

Coles MG, Gratton G, Donchin E (1988) Detecting early communication: using measures of movement-related potentials to illuminate human information processing. Biol Psychol 26:69-89. CrossRef Medline

Coxon JP, Stinear CM, Byblow WD (2006) Intracortical inhibition during volitional inhibition of prepared action. J Neurophysiol 95:3371-3383. CrossRef Medline

Davare M, Duque J, Vandermeeren Y, Thonnard JL, Olivier E (2007) Role of the ipsilateral primary motor cortex in controlling the timing of hand muscle recruitment. Cereb Cortex 17:353-362. Medline

Devanne H, Lavoie BA, CapadayC (1997) Input-output properties and gain changes in the human corticospinal pathway. Exp Brain Res 114:329-338. CrossRef Medline

Di Lazzaro V, Oliviero A, Profice P, Insola A, Mazzone P, Tonali P, Rothwell JC (1999) Direct demonstration of interhemispheric inhibition of the human motor cortex produced by transcranial magnetic stimulation. Exp Brain Res 124:520-524. Medline

Duque J, Mazzocchio R, Dambrosia J, Murase N, Olivier E, Cohen LG (2005) Kinematically specific interhemispheric inhibition operating in the process of generation of a voluntary movement. Cereb Cortex 15:588-593. Medline

Duque J, Lew D, Mazzocchio R, Olivier E, Ivry RB (2010) Evidence for two concurrent inhibitory mechanisms during response preparation. J Neurosci 30:3793-3802. CrossRef Medline

Ferbert A, Priori A, Rothwell JC, Day BL, Colebatch JG, Marsden CD (1992) Interhemispheric inhibition of the human motor cortex. J Physiol 453: 525-546. Medline

Ganguly K, Secundo L, Ranade G, Orsborn A, Chang EF, Dimitrov DF, Wallis JD, Barbaro NM, Knight RT, Carmena JM (2009) Cortical representation of ipsilateral arm movements in monkey and man. J Neurosci 29: 12948-12956. CrossRef Medline

Gerloff C, Cohen LG, Floeter MK, Chen R, Corwell B, Hallett M (1998) Inhibitory influence of the ipsilateral motor cortex on responses to stimulation of the human cortex and pyramidal tract. J Physiol 510:249-259. CrossRef Medline

Giovannelli F, Borgheresi A, Balestrieri F, Zaccara G, Viggiano MP, Cincotta M, Ziemann U (2009) Modulation of interhemispheric inhibition by volitional motor activity: an ipsilateral silent period study. J Physiol 587: 5393-5410. CrossRef Medline

Guiard Y, Requin J (1977) Interhemispheric sharing of signals and responses and the psychological refractory period. Neuropsychologia 15: 427-438. CrossRef Medline

Heise KF, Steven B, Liuzzi G, Thomalla G, Jonas M, Müller-Vahl K, Sauseng P, Münchau A, Gerloff C, Hummel FC (2010) Altered modulation of intracortical excitability during movement preparation in Gilles de la Tourette syndrome. Brain 133:580-590. CrossRef Medline

Hortobágyi T, Taylor JL, Petersen NT, Russell G, Gandevia SC (2003) Changes in segmental and motor cortical output with contralateral mus- cle contractions and altered sensory inputs in humans. J Neurophysiol 90:2451-2459. CrossRef Medline

Hübers A, Orekhov Y, Ziemann U (2008) Interhemispheric motor inhibition: its role in controlling electromyographic mirror activity. Eur J Neurosci 28:364-371. CrossRef Medline

Kobayashi M (2010) Effect of slow repetitive TMS of the motor cortex on ipsilateral sequential simple finger movements and motor skill learning. Restor Neurol Neurosci 28:437-448. Medline

Lee H, Gunraj C, Chen R (2007) The effects of inhibitory and facilitatory intracortical circuits on interhemispheric inhibition in the human motor cortex. J Physiol 580:1021-1032. CrossRef Medline

Lemay M, Chouinard S, Richer F, Lesperance P (2008) Huntington's disease affects movement termination. Behav Brain Res 187:153-158. CrossRef Medline

Leocani L, Cohen LG, Wassermann EM, Ikoma K, Hallett M (2000) Human corticospinal excitability evaluated with transcranial magnetic stimulation during different reaction time paradigms. Brain 123:1161-1173. CrossRef Medline

Liuzzi G, Hörniss V, Hoppe J, Heise K, Zimerman M, Gerloff C, Hummel FC (2010) Distinct temporospatial interhemispheric interactions in the human primary and premotor cortex during movement preparation. Cereb Cortex 20:1323-1331. CrossRef Medline

Matthews PB (1999) The effect of firing on the excitability of a model motoneurone and its implications for cortical stimulation. J Physiol 518:867882. CrossRef Medline

Meyer BU, Voss M (2000) Delay of the execution of rapid finger movement by magnetic stimulation of the ipsilateral hand-associated motor cortex. Exp Brain Res 134:477-482. CrossRef Medline

Meyer BU, Röricht S, Gräfin von Einsiedel H, Kruggel F, Weindl A (1995) Inhibitory and excitatory interhemispheric transfers between motor cortical areas in normal humans and patients with abnormalities of the corpus callosum. Brain 118:429-440. CrossRef Medline

Moran DW, Schwartz AB (1999) Motor cortical representation of speed and direction during reaching. J Neurophysiol 82:2676-2692. Medline

Muellbacher W, Facchini S, Boroojerdi B, Hallett M (2000) Changes in motor cortex excitability during ipsilateral hand muscle activation in humans. Clin Neurophysiol 111:344-349. CrossRef Medline

Murase N, Duque J, Mazzocchio R, Cohen LG (2004) Influence of interhemispheric interactions on motor function in chronic stroke. Ann Neurol 55:400-409. CrossRef Medline

Nelson AJ, Hoque T, Gunraj C, Ni Z, Chen R (2009) Bi-directional interhemispheric inhibition during unimanual sustained contractions. BMC Neurosci 10:31. CrossRef Medline

Noorani I, Gao MJ, Pearson BC, Carpenter RH (2011) Predicting the timing of wrong decisions with LATER. Exp Brain Res 209:587-598. CrossRef Medline

Perez MA (2012) The functional role of interhemispheric interactions in human motor control. In: Cortical connectivity: brain stimulation for assessing and modulating cortical connectivity and function. (Chen R, Rothwell J, eds), pp 165-181. Berlin: Springer.

Perez MA, Cohen LG (2008) Mechanisms underlying functional changes in the primary motor cortex ipsilateral to an active hand. J Neurosci 28: 5631-5640. CrossRef Medline

Perez MA, Wise SP, Willingham DT, Cohen LG (2007) Neurophysiological mechanisms involved in transfer of procedural knowledge. J Neurosci 27:1045-1053. CrossRef Medline

Perez MA, Soteropoulos DS, Baker SN (2012) Corticomuscular coherence during bilateral isometric arm voluntary contractions in healthy humans. J Neurophysiol 107:2154-2162. CrossRef Medline

Reynolds C, Ashby P (1999) Inhibition in the human motor cortex is reduced just before a voluntary contraction. Neurology 53:730-735. CrossRef Medline

Ridding MC, Brouwer B, Nordstrom MA (2000) Reduced interhemispheric inhibition in musicians. Exp Brain Res 133:249-253. CrossRef Medline

Riehle A, Requin J (1989) Monkey primary motor and premotor cortex: single-cell activity related to prior information about direction and extent of an intended movement. J Neurophysiol 61:534-549. Medline

Rothwell JC, Hallett M, Berardelli A, Eisen A, Rossini P, Paulus W (1999) Magnetic stimulation: motor evoked potentials. The International Feder- 
ation of Clinical Neurophysiology. Electroencephalogr Clin Neurophysiol Suppl 52:97-103. Medline

Sakai K, Ugawa Y, Terao Y, Hanajima R, Furubayashi T, Kanazawa I (1997) Preferential activation of different I waves by transcranial magnetic stimulation with a figure-of-eight-shaped coil. Exp Brain Res 113:24-32. CrossRef Medline

Sinclair C, Hammond GR (2008) Reduced intracortical inhibition during the foreperiod of a warned reaction time task. Exp Brain Res 186:385-392. CrossRef Medline

Soteropoulos DS, Baker SN (2007) Different contributions of the corpus callosum and cerebellum to motor coordination in monkey. J Neurophysiol 98:2962-2973. CrossRef Medline

Soteropoulos DS, Perez MA (2011) Physiological changes underlying bilateral isometric arm voluntary contractions in healthy humans. J Neurophysiol 105:1594-1602. CrossRef Medline

Stedman A, Davey NJ, Ellaway PH (1998) Facilitation of human first dorsal interosseous muscle responses to transcranial magnetic stimulation during voluntary contraction of the contralateral homonymous muscle. Muscle Nerve 21:1033-1039. CrossRef Medline

Tazoe T, Sasada S, Sakamoto M, Komiyama T (2013) Modulation of inter- hemispheric interactions across symmetric and asymmetric bimanual force regulations. Eur J Neurosci 37:96-104. CrossRef Medline

Thorns J, Wieringa BM, Mohammadi B, Hammer A, Dengler R, Münte TF (2010) Movement initiation and inhibition are impaired in amyotrophic lateral sclerosis. Exp Neurol 224:389-394. CrossRef Medline

Trompetto C, Bove M, Marinelli L, Avanzino L, Buccolieri A, Abbruzzese G (2004) Suppression of the transcallosal motor output: a transcranial magnetic stimulation study in healthy subjects. Exp Brain Res 158:133-140. Medline

Verbruggen F, Logan GD (2009) Models of response inhibition in the stopsignal and stop-change paradigms. Neurosci Biobehav Rev 33:647-661. CrossRef Medline

Yedimenko JA, Perez MA (2010) The effect of bilateral isometric forces in different directions on motor cortical function in humans. J Neurophysiol 104:2922-2931. CrossRef Medline

Zimerman M, Heise KF, GerloffC, Cohen LG, Hummel FC (2012) Disrupting the ipsilateral motor cortex interferes with training of a complex motor task in older adults. Cereb Cortex. Advance online publication. Retrieved Dec. 13, 2012. doi:10.1093/cercor/bhs385. CrossRef Medline 